\title{
Effects of selected therapeutic aerobic exercise on remedial case of premenstrual syndrome in case of Arba Minch University
}

\author{
Abebe K. ${ }^{\mathrm{ABCDC}}$, Deyuo M. ${ }^{2 \mathrm{ACE}}$, Aychiluhim W. ${ }^{3 \mathrm{ABCDE}}$ \\ ${ }^{1}$ Department of Sport Science, Arba Minch University, Arba Minch, Ethiopia \\ ${ }^{2}$ Department of Sport Science, Arba Minch University, Arba Minch, Ethiopia \\ ${ }^{3}$ Department of Sport Science, Hawassa University, Hawassa, Ethiopia
}

Authors' Contribution: A - Study design; B - Data collection; C - Statistical analysis; D - Manuscript preparation; E - Funds collection.

\begin{abstract}
Purpose: $\quad$ The purpose of this study was to assess the effect of selected therapeutic 12 weeks regular aerobic exercise on remedial case of premenstrual syndrome students.

Material: $\quad$ A quasi-experimental study was used on a randomly selected 30 female students aged 18 to 30 years who meet the eligibility criteria at Arba Minch University. Participants were divided in to two groups: experimental group $(n=15)$ and control group $(n=15)$ for comparison purpose. The therapeutic aerobic exercise duration was 40-60 minutes and carried out for 12 weeks with three sessions per week. In this study the premenstrual symptoms questionnaire consists of 8 domains of used. The domains were pain, concentration, behavioral change, autonomic reactions, water retention, negative effect, arousal and control. A paired t-test statistical method was used for data analysis. SPSS version 20 was used for data management and analysis.

Results: $\quad$ The study found mean scores of negative reaction decreased after 12 weeks with a frequency of 3 per week therapeutic aerobic training in the experimental group but not in the control. Further, a statistically significant change was observed for all measured variables for experimental group. However, there was no a statistically significant change for the controls. The selected therapeutic aerobic exercise training program on treating premenstrual syndrome had a significance effects on experimental group and students who practiced for twelve weeks with a repetition of three times per week.

Conclusions: Twelve weeks of regular therapeutic aerobic exercise with three sessions per a week with intensity of 40 to 60 minutes reduces the severity of feeling premenstrual syndrome symptoms (PMS).

Keywords: premenstrual, syndrome, therapeutic, aerobic exercise, remedial case.
\end{abstract}

\section{Introduction}

Premenstrual syndrome (PMS) is a condition occurring in the luteal phase of the menstrual cycle prior to the onset of women's menstrual period. PMS is an array of predictable physical, cognitive, effective and behavioral symptoms that occur cyclically during luteal phase of menstrual cycle [1]. It is estimated that up to $90 \%$ of women who menstruate experience at least one premenstrual symptoms, it occurs within the two weeks before menses and easing after menstruation begin [2]. PMS is estimated to occur in $8-20 \%$ of women's and substantially reduce quality of life [3]. PMS starts during puberty years and continues to menopausal period. PMS manifests itself during every month's luteal stage in the form of somatic, psychological and behavioral disorder. It occurs in $90 \%$ of all women's reproductive age and about $10 \%$ have diagnosed as having premenstrual dysphonic disorder [4]. Over 300 PMS symptoms range from emotional and behavioral symptoms. Some of them are depression, angry out bursts, irritability, crying spells, anxiety, confusion, social with drawl, poor concentration , sleep disturbance, thirst and appetite changes. The physical symptoms include breast tenderness, bloating and weight gain, headache, swelling of the hands or feet and aches or pains [5]. It was reported that behavioral changes, suicide attempts, absent from class, Hospital admission and increased prone accidents can

(C) Abebe K., Deyuo M., Aychiluhim W., 2019

doi:10.15561/18189172.2019.0201 be aggravated premenstrual syndrome. PMS caused by an underlying neurobiological venerability to normal fluctuations in the circulating sex hormone (estrogen and progesterone level) during the menstrual cycle [6]. The role of sex steroids in PMS is supported by observations that symptoms often improve with treatments resulting in ovulation suppression [7]. More studies suggested that PMS is uncommon in an ovulatory menstrual cycle, and women's with elevated level of sex hormones have more severe symptoms [8]. Evidence suggested that PMS is not a single condition but asset of inter related complex symptoms with multiple genotypes, phenotypes or subtypes and sexual different pathophysiologic events that being with ovulation [9, 10]. Gannon L [11] found that the length of time women had been regular exercise correlated significantly with lower level of menstrual symptoms via correlation of neuroendocrine abnormality. PMS symptoms must be present in the 5 days before women's periods for at list three menstrual cycles in the arrow and end within 4 days after the period starts. Symptoms most interfere with normal life activities, and sexual relationships. There are no universally accepted diagnostic criteria for PMS. Therapeutic aerobic exercise recommended as a method to reduce PMS occurrence and severity. Recommended aerobic exercise, in particular to reduce fatigue and depression associated with PMS [12]. The U.S department of health and human services recommends regular aerobic activity as treatment for PMS. Same sources suggested that aerobic exercise is an 
effective alternative pharmaceutical treatment in easing PMS [13].

The purpose of the present study is to investigate the effect of selected therapeutic aerobic exercise on remedial case of premenstrual syndrome in case of Arba Minch University Female students. Finally we hypothesized that, there is or no significant difference in experience of premenstrual syndrome between experimental and control groups after 12 week aerobic exercise.

\section{Material and methods}

Participants. Thirty volunteer university female students selected by using simple random sampling technique. The age group was limited from $18-30$ years those who fulfill eligibility criterion were considered as target group. The participants were divided in to two balanced groups experimental and control groups.

Research design. Quasi-experimental research design study was implemented. Twelve weeks of therapeutic aerobic exercise program was given only for experimental group. The control group did not participate in any of the training program. Data on selected participant's premenstrual symptoms was collected before and after training. Menstrual symptom questionnaire (MSQ) was used and the eligible participants were instructed to fill the questionnaire before and after training [14]. The privacy of the participants was protected with written consent provided which was approved by medical school in Arba Minch University. The study conducted during March May 2017 in Arba Minch University.

Exercise training protocol. Therapeutic Aerobic exercise program was done for a period of 12 weeks of 3 sessions (Monday, Wednesday and Friday from 6:007:00 am.) per week with 40-60 minutes for each session with the instruction of experienced trainer. At the start of the exercise, 10 min warm up was performed, then the rapid movements of limbs and trunk in combined manner (main part of training) for $40 \mathrm{~min}$ and $10 \mathrm{~min}$ light stretching were done. The training program consisted of aerobic exercise; treadmill running, walking, swimming, team sport, aerobic dance. These exercise programs were performed between the two menstrual cycles. Before and after training programm the questioner distributed among the subjects of the groups.

Inclusive and exclusive criteria.

Study subjects filled the health history questionnaire and they were included who have a regular menstrual cycle, bleeding between menstrual cycles of length of 22-35 days for 3-7 days was included with age between 18 and 30 years. However, subjects were excluded having a regular physical activity for 3 months before starting the study. History of disease and PMS standard compliant check list which contains 30 cases. Finally, all participants underwent health examination to ensure that they were not taking any medications (including anti-pregnancy medications).

Statistical Analysis. The data was analyzed using a statistical Package for Social Sciences (SPSS) version 20.0 for IBM. Descriptive statistical measures within experimental and control groups (mean, standard deviation and standard errors) were computed. Further, inferential statistics (paired t-test and confidence interval) was made within experimental groups to compare before and after exercise effects on premenstrual symptom variables. The statistical significance was asset at a level of $5 \%$.

\section{Results}

The descriptive measures and confidence intervals on pain are presented in Table 1 . The mean pain difference for the experimental group was $21.667 \pm 3.266$ while the control group was $1.467 \pm 2.446$. Table 1 depicts, there is a significance difference before and after exercise on pain for the experimental group but not for control group. This indicted that, exercise intervention has lessened subjects experience physical pains during the premenstrual period.

From Table 2, there was significant difference in the pre and posttest scores on concentration of experimental group with the mean value $23.267 \pm 1.907$, whereas there was no significant difference between pre and post scores on concentration for control group. Hence, intervention

Table 1. Pre and post mean differences of experimental and control group for pain

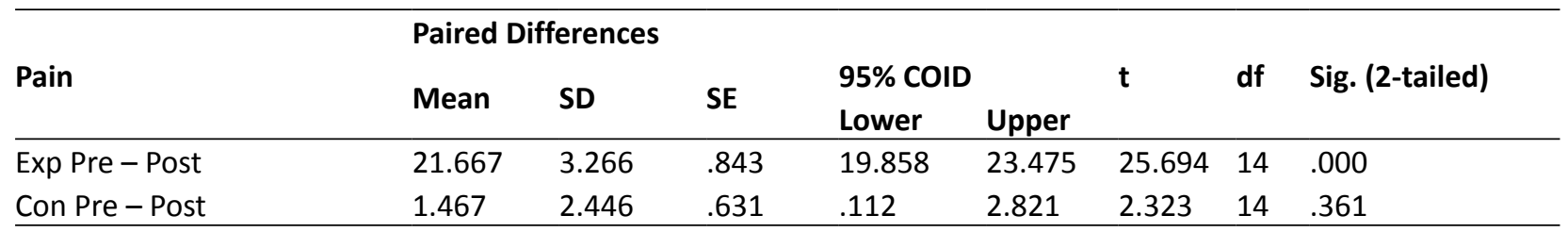

Exp $=$ experimental, Pre =pretest, Con = control group $\mathrm{N}=$ number of subject, $\mathrm{SD}=$ standard deviation of mean $\mathrm{SE}=\mathrm{Std}$. Error Mean $\mathrm{CIOD}=$ Confidence Interval of the difference

Table 2. Pre and post mean differences of experimental and control group for concentration

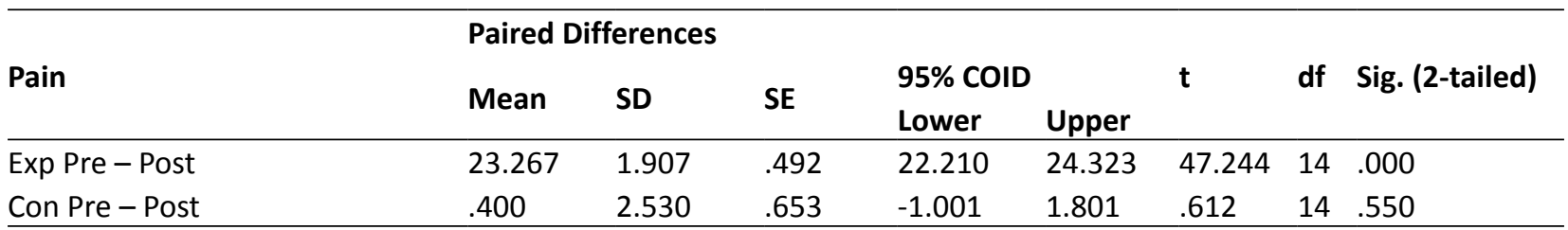


brought a significant change on the concentration problems.

From Table 3, the mean behavioral change after and before difference was higher for experimental group than control group. Also, the difference was highly significant for experimental group while it was insignificant for the control group. This indicated that after the intervention, positive change was explored in relation to work performance and social activities in the experimental group, which negatively responded during the premenstrual period.

Table 4 shows the effects of aerobic training program on reducing automatic reaction sign of PMS in the experimental and control groups. As it depicts, in experimental group, mean automatic reaction before, and after the training showed a significant difference. However, there is no significant difference in the control group. This depicts that after the intervention positive changes on the automatic reactions such as nausea, dizziness, cold sweet and hot flash was reported by subjects in experimental group. On the other hand, subjects in the control group reported the same automatic responses that they have reported in their pre-test.

From table 5 there was significant difference in pre and post test scores on water retention for experimental group with the mean value $23.600 \pm 2.293$ whereas there was no significant difference between pre and post scores on water retention for control group .933 \pm 2.154 . This result indicates that therapeutic Aerobic exercise significantly decreased the problem water retention related problem such as, painful breast, swelling, skin disorders of subjects.

Table 6 shows; there was significant difference in pre and post test scores on negative reaction for experimental group with the mean value $12.333 \pm 1.718$ where as in control group there was no significant difference between pre and post scores on negative effect with the mean value $.667 \pm 1.543$. This result depicts that after the intervention positive changes reported in treatment group subjects. Positive psychological related changes reported such as loneliness, anxiety, depression mood swing and restlessness.

The descriptive measures and confidence intervals on arousal are presented in Table 7 . The mean of arousal for the experimental group was $14.467 \pm 1.959$ while the control group was $-.333 \pm 1.543$. This result depicts that after the intervention positive changes reported on arousal related such as, feeling of well-being, excitement, affectionate and burst of energy.

Table 3. Pre and post mean differences of experimental and control group for behavioral change

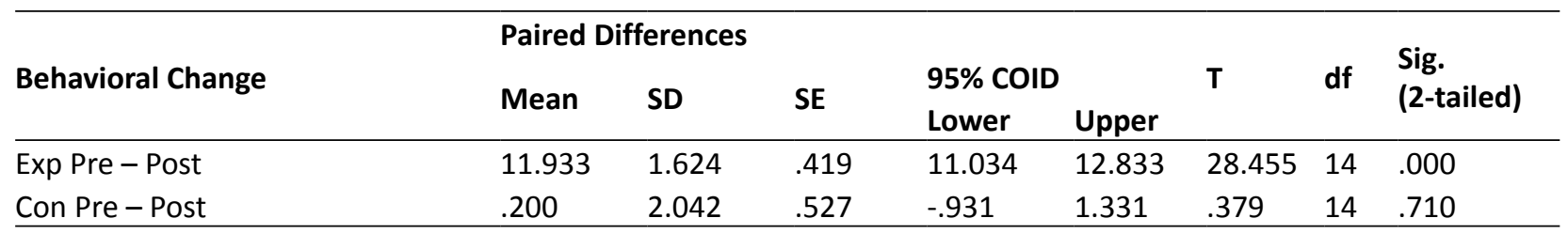

Table 4. pre and post mean differences of experimental and control group for autonomic reaction

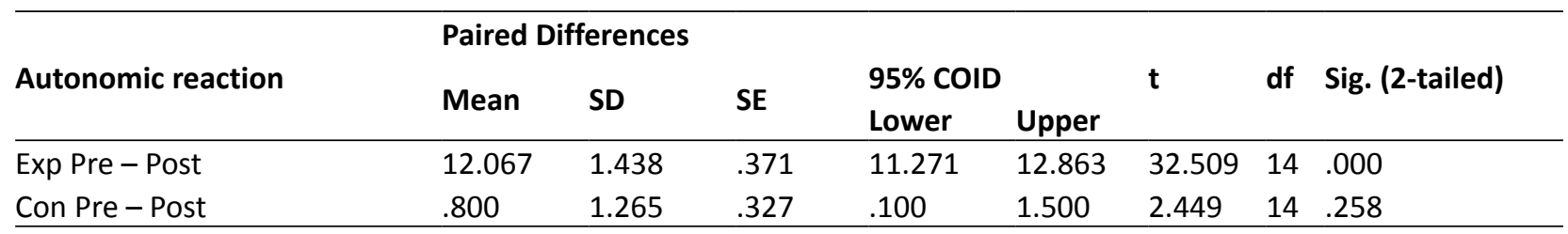

Table 5. Pre and post mean differences of experimental and control group for water retention

\begin{tabular}{|c|c|c|c|c|c|c|c|c|}
\hline \multirow{3}{*}{ Water retention } & \multicolumn{8}{|c|}{ Paired Differences } \\
\hline & \multirow{2}{*}{ Mean } & \multirow{2}{*}{ SD } & \multirow{2}{*}{ SE } & \multicolumn{2}{|c|}{ 95\% COID } & \multirow[t]{2}{*}{$\mathbf{t}$} & \multirow[t]{2}{*}{ df } & \multirow[t]{2}{*}{ Sig. (2-tailed) } \\
\hline & & & & Lower & Upper & & & \\
\hline Exp Pre - Post & 23.600 & 2.293 & .592 & 22.330 & 24.870 & 39.864 & 14 & .000 \\
\hline Con Pre - Post & .933 & 2.154 & .556 & -.259 & 2.126 & 1.678 & 14 & .115 \\
\hline
\end{tabular}

Table 6. Pre and post mean differences of experimental and control groups for negative reaction

\section{Paired Differences}

\begin{tabular}{|c|c|c|c|c|c|c|c|c|}
\hline \multirow[t]{2}{*}{ Negative reaction } & \multirow{2}{*}{ Mean } & \multirow{2}{*}{ SD } & \multirow{2}{*}{ SE } & \multicolumn{2}{|c|}{ 95\% COID } & \multirow[t]{2}{*}{$\mathbf{t}$} & \multirow[t]{2}{*}{ df } & \multirow[t]{2}{*}{ Sig. (2-tailed) } \\
\hline & & & & Lower & Upper & & & \\
\hline Exp Pre-Post & 12.333 & 1.718 & .444 & 11.382 & 13.285 & 27.800 & 14 & .000 \\
\hline Con Pre - Post & .667 & 1.543 & .398 & -.188 & 1.521 & 1.673 & 14 & .156 \\
\hline
\end{tabular}


Table 7. Pre and post mean differences of experimental and control groups for arousal

Paired Differences

\begin{tabular}{llllllllll} 
Arousal & \multirow{2}{*}{ Mean } & SD & SE & \multicolumn{2}{c}{ 95\% COID } & t & \multicolumn{2}{c}{ df } & Sig. (2-tailed) \\
& & & & Lower & Upper & & & \\
\hline Exp Pre-Post & 14.467 & 1.959 & .506 & 13.382 & 15.552 & 28.599 & 14 & .000 \\
Con Pre-Post & -.333 & 1.543 & .398 & -1.188 & .521 & -.837 & 14 & .417 \\
\hline
\end{tabular}

\section{Discussion}

The purpose of this study was to assess the effect of selected therapeutic aerobic exercise on remedial case of premenstrual syndrome. The study showed the experimental group experienced a decreased significant change in physical symptom of pain and psychological symptoms of concentration. A study done by Khadmi et al [15] on 8 weeks aerobic exercise (such as swimming) found that decrease in physical and psychological symptom which is in line with this study. The above result also supported by Dehghan et al [16] study on 3-month aerobic exercise reduces physical and psychological symptoms. On the other hand a study conducted by Pablo (17) on 8 week of aerobic exercise as treatment for reducing symptoms concentration the experimental group showed increased behavioral changes and water retention after intervention. However, there was no significant difference of behavioral change and water retention of premenstrual syndrome in control group. Similarly, the study depicts that after intervention positive change related on the automatic reactions symptoms such as nausea, dizziness, cold sweet and hot flash reported by subjects in experimental group. However, subjects in the control group reported the same automatic responses that they have reported in their pre-test and posttest. The result was supported by the finding of Zinat Chanbari et al [18] conducted a study on link between exercise and improved in negative mood state results decrease autonomic reaction. The study also indicated that aerobic exercise increase in estrogen and progesterone. Aganof [19] also demonstrate that PMS display health full changes in water retention due to aerobic exercise training. Regular aerobic exercise affect estrogen and progesterone level [20].

The study result depicts that positive psychological changes reported negative effects related symptoms (loneliness, anxiety, depression, mood swing and restlessness). Arousal level also (feeling of well-being, excitement, affectionate and burst of energy) and control symptoms (chest pains, heart pounding, numbness, feeling of suffocation and ringing in ears) after the intervention positive changes were reported in treatment group subjects. However, no significant changes reported related to negative effect and arousal level in control group. In line with the present study Weismann \& Gottlieb A, [21, 24] the study conducted on the link between exercise and improvement in negative mood state and found a decrease negative mood state. The present result also supported by JA Blumenthal \& Weinberger [22, 23] found that moderate regular aerobic exercise decrease negative effect. The result was supported by Gottlieb A, [24] aerobic exercise can decrease, negative mood state and menstrual cycle symptoms.

\section{Conclusion}

This study concluded that moderate-intensity selected therapeutic aerobic exercise for 12 weeks was able to decrease premenstrual syndrome symptoms of concentration, behavioral change, autonomic reactions, water retention, negative effect, arousal and control in the treatment group; however, in control group did not show decrement the listed PMS problem was observed in students of Arba Minch University. The effect of therapeutic aerobic exercise training should be promoted to patients suffering from PMS, which helps to reduce symptoms.

\section{Conflict of interest}

The authors declare no conflict of interest.

\section{Reference}

1. Braver man PK. Premenstrual syndrome and premenstrual dysphonic Disorder. $J$ Pediatric Adolescent Gynecol. 2007; 20:3-12. https://doi.org/10.1016/j.jpag.2006.10.007

2. Premenstrual syndrome: Number 155 - April 1995 (Replaces No. 66, January 1989) Committee on Gynecologic Practice. International Journal of Gynecology \& Obstetrics. 1995;50(1):80-4. https://doi.org/10.1016/0020-7292(95)90002-0

3. Deuster PA, Adera T. South-Paul, Biological, Social, and Behavioral factors associated with premenstrual syndrome. Arch. Fam. Med. 1999;8(2):122-128.

4. Ismail KHM, O'Brien S. Premenstrual syndrome. CurrObstet Gynecol. 2005; 15:25-30 https://doi.org/10.1007/s13224-011-0117-5
5. Halbreich U. The diagnosis of premenstrual syndrome and premenstrual dysphonic disorder-clinical procedures research perspectives. Gynecol Endocrinol. 2004; 19:320.

6. Mortola JF, Assessment and management of premenstrual syndrome. Curr.Opin.Obstet.Gynecol. 1992; 4(6):877-885.

7. Daley A. Exercise and premenstrual symptomatology: a comprehensive review. $J$. Women's Health. (Larchmt), 2009;18(6):895-899. https://doi.org/10.1089/jwh.2008.1098

8. Halbreich U. The Etiology, Biology, and evolving Pathology of premenstrual syndromes. Psycho neuroendocrinology, 2003; 3: 55-99. https://doi.org/10.1016/S0306-4530(03)00097-0

9. Indhusekar R, Usman SB, O’Brien S. Psychological aspects of premenstrual syndrome. Best Pract Res Clin Obstet Gynecol. 2007; 21(2): 207-20. 
https://doi.org/10.1016/j.bpobgyn.2006.10.002

10.Johnson WG, Carr-Nangle RE, Bergeron KC. Macronutrient intake, eating habits, and exercise as moderators of menstrual distress in healthy women. Psychosom. Med. 1995; 57(4):324-330.

11.Gannon L, The potential role of exercise in the alleviation of menstrual disorders and menopausal symptoms: a theoretical synthesis of recent research. Women Health. 1988; 14(2): 105-127. https://doi.org/10.1300/J013v14n02_07

12.Guner Cicek. The effect of regular aerobic exercises on premenstrual syndrome in sedentary women. Baltic Journal of Health and Physical Activity, 2018; 10(2): 34-42. https://doi.org/10.29359/BJHPA.10.2.04

13.Halbreich U, Backstrom T, Eriksson E, O'Brien S, Calil H, Ceskova $\mathrm{E}$, et al. Clinical diagnostic criteria for premenstrual syndrome and guidelines for their quantification for research studies. Gynecol. Endocrinol. 2007; 23(3):123-130.

14.Margaret A. Chesney Donald L, TastoTaso. The development of the menstrual symptom questionnaire. Behavior research and Therapy, 1975;13(4):237-44. https://doi.org/10.1016/0005-7967(75)90028-5

15.Khademi A, Tabatabaeefar L, Akbari E. Comparison of prevalence of premenstrual syndrome in swimmer and nonswimmer students. Act Med Iran. 2008; 46:307-13.

16.Dehghan MF, Emami M Dhamkar L. The effect of 3 month regular exercise on premenstrual symptoms. J Med Sic Rafsanjan, 2008; 7: 89-98.
17.Pablo Cerda. CervelloE, CoccaA, Vicciana J. Effect of Aerobic exercise training program as complimentary therapy in-patient withmoderate depression. PerceptMot Skills. 2011;112:761-9. https://doi.org/10.2466/02.15.PMS.112.3.761-769

18.Zinat Chanbari, M.D, Farideh Dehghan Manshval, M.D, Mina Jafarabadl, M.D. The effect of three months regular aerobic exercise on premenstrual syndrome. Journal of reproductive health, 2008 ,2(4):167-171.

19.Aganoff JA, Boyle GJ. Aerobic exercise, mood states and menstrual cycle symptoms. J. Psychosom. 1994; 183-192.

20.Dell DL, Premenstrual syndrome, premenstrual dysphonic disorder, and premenstrual exacerbation of another disorder. Clin. Obstet.Gynecol. 2004; 47(3):568- 575. https://doi.org/10.1007/978-0-387-78665-0_115

21.Weismann AM, Hertz AJ, Hansen MD, Johnson SR. The natural history of primary dysmenorrhea: a longitudinal Study. BJOG, 2004; 111(4): 354-352.

22.Blumenthal JA, Williams S, Needles TL, Wallace AG. Psychological changes accompany aerobic exercise in healthy middle-aged adults. Psychosom. 1982; 44: 529-536. https://doi.org/10.1097/00006842-198212000-00004

23. Weinberg A Jackson, Kolodny K. The relationship of massage and exercise to mood enhancement. The Sport Psychologist. 1988; 2: 202-211. https://doi.org/10.1123/tsp.2.3.202

24.Gottlieb A, American premenstrual syndrome. A mute voice. Anthropology Today, JSTOR, 1988; 4(6): 10- 13. https://doi.org/10:2307/3032946

\section{Information about the authors:}

Abebe K.; (Corresponding author); http://orcid.org/0000-0001-6192-8388; Kalkidana897@gmail.com; Department of Sport Science, Arba Minch University; P.O. Box 21, Arba Minch, Ethiopia.

Deyuo M.; http://orcid.org/0000-0001-6017-1707; Moladeyu10@gmail.com; Department of Sport Science, Arba Minch University; P.O. Box 21, Arba Minch, Ethiopia.

Aychiluhim W.; http://orcid.org/0000-0002-7279-2743; Wondeayi81@gmail.com; Department of Sport Science, Hawassa University; Hawassa, Ethiopia.

Cite this article as:

Abebe K, Deyuo M, Aychiluhim W. Effects of selected therapeutic aerobic exercise on remedial case of premenstrual syndrome in case of Arba Minch University. Pedagogics, psychology, medical-biological problems of physical training and sports, 2019;23(2):54-58.

https://doi.org/10.15561/18189172.2019.0201

The electronic version of this article is the complete one and can be found online at: https://www.sportpedagogy.org.ua/index.php/PPS/issue/archive

This is an Open Access article distributed under the terms of the Creative Commons Attribution License, which permits unrestricted use, distribution, and reproduction in any medium, provided the original work is properly cited (http://creativecommons.org/licenses/by/4.0/deed.en).

Received: 12.02 .2019

Accepted: 10.03.2019; Published: 30.04.2019 